\title{
An Ultrasensitive Electrochemical DNA Biosensor Based on Carboxylated Multi-walled Carbon Nanotube/Molybdenum Disulfide Composites for KRAS Gene Detection
}

\author{
Xiaojing WAng,* Mei YANG, *† Qingyan LiU,* Siyi YANG,* Xintong Geng,* Yixia YANG,* \\ Huanbao FA, ** Yongzhong WANG, * and Changjun Hou* \\ *Key Laboratory of Biorheological Science and Technology, Ministry of Education, College of Bioengineering, \\ Chongqing University, Chongqing 400044, P. R. China \\ **College of Chemistry and Chemical Engineering, Chongqing University, Chongqing 400044, P. R. China
}

\begin{abstract}
In this paper, an ultrasensitive electrochemical biosensor based on carboxylated multi-walled carbon nanotube/molybdenum disulfide composites (MWCNTs-COOH/MoS 2 ) for the detection of KRAS gene is described. An easy, low-cost method, named one-step hydrothermal, was used for the synthesize of MWCNTs-COOH/MoS 2 nanocomposites, and scanning electronic microscopy (SEM), high resolution transmission electron microscopy (HRTEM), Fourier transform infrared spectroscopy (FT-IR), X-ray photoelectron spectroscopy (XPS) and X-ray diffraction (XRD) were used for characterizing the prepared composites. Furthermore, cyclic voltammetry (CV) and differential pulse voltammetry (DPV) were employed for an electrochemical performance study of this biosensor. Under optimal conditions, the detection limit of target DNA achieved down to $3 \mathrm{fM}(S / N=3)$ with high sensitivity; the linear range with the logarithm of the concentrations of target DNA varied from $1.0 \times 10^{-14}$ to $1.0 \times 10^{-7} \mathrm{M}$. Finally, the practicality of our proposed sensor was verified by a determination of the KRAS gene in human serum samples with good accuracy and high precision due to the excellent conductivity and large active surface area of the MWCNTs-COOH/MoS 2 nanocomposites. This proposed biosensor thus provides a practical method for the rapid and sensitive analysis of gene detection.
\end{abstract}

Keywords KRAS gene, carboxylated multi-walled carbon nanotube/molybdenum disulfide composites, electrochemical DNA biosensor

(Received November 20, 2018; Accepted December 15, 2018; Advance Publication Released Online by J-STAGE December 28, 2018)

\section{Introduction}

Methods of cancer screening, where the detection of specific oligonucleotide sequences plays a great important role, has drawn attention of researchers from various fields. Different analytical technologies have been developed, such as PCR, ${ }^{1-3}$ next generation sequencing (NGS), ${ }^{4-6} \mathrm{HPLC}^{7}$ and so on However, these technologies rely on professional skills and high cost. In order to find a more convenient method for oligonucleotide sequence detection, researchers are combining the advantages of complementary base pairing of gene with other fields, such as electrochemiluminescence, ${ }^{8}$ electrochemistry, ${ }^{9,10}$ chemiluminescence,${ }^{11}$ fluorescence ${ }^{12-15}$ and nanotechnology. ${ }^{16}$ Herein, electrochemical DNA biosensors have received much interest concerning the property that they can provide a simpler and more cost-effective platform that is highly sensitive for DNA detection.

To enhance the detection performance of an electrochemical DNA or RNA biosensor, different kinds of signal amplification strategies have been introduced to greatly improve the sensitivity and stability of novel biosensors; for example, nanomaterials

† To whom correspondence should be addressed.

E-mail: yangmei@cqu.edu.cn have been designed to provide a promising sensing platform, such as carbon nanotubes (CNTs), 3D graphene, metal nanoparticles, metal oxide nanoparticles. ${ }^{17-20}$ Moreover, twodimensional (2D) layered materials, ${ }^{21}$ which we are already familiar with, such as tungsten disulfide $\left(\mathrm{WS}_{2}\right)$ and molybdenum disulfide $\left(\mathrm{MoS}_{2}\right)$, are popular due to the advantage of photocatalysis, electrocatalysis, electronic and electrochemical properties. $\mathrm{MoS}_{2}$ is one kind of transitionmetal sulfides and is now becoming an attractively hot material owing to its remarkable optical properties and excellent electrical performance, which are derived from the unique stacking S-Mo-S structure through weak van der Waals interactions. ${ }^{22,23}$ To improve the poor conductivity of $\mathrm{MoS}_{2},{ }^{24-26}$ the combination of $\mathrm{MoS}_{2}$ and other materials, like graphene, MWCNTs, AuNPs, $\mathrm{ZnO}$, polyaniline (PANI), quantum dots (QDs), effectively broadens the properties of $\mathrm{MoS}_{2} \cdot{ }^{27-33}$ By using Au nanoparticles and hollow $\mathrm{MoS}_{2}$ microcubes, a binding biosensor for miRNA-21 superior detection was fabricated, along with another signal amplification strategy, the detection limit reached to $0.086 \mathrm{fM}(S / N=3) .{ }^{34}$ To investigate the DNA hybridization process, an ultrasensitive surface plasmon resonance (SPR) biosensor was investigated. ${ }^{35}$ The novel application that combined $\mathrm{MoS}_{2}$ with $\mathrm{Au}$ nanoparticles and graphene greatly increased the sensitivity and accuracy of the SPR biosensor. Therefore, we can see the great potential of the $\mathrm{MoS}_{2}$ 


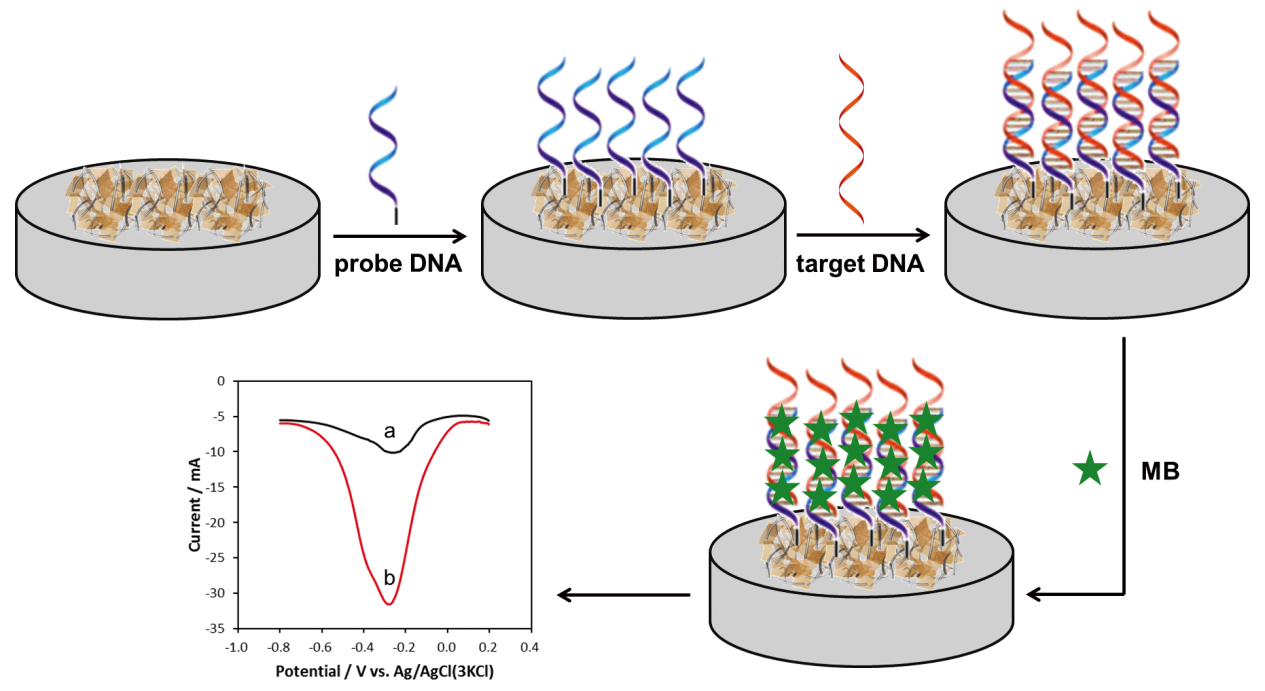

Scheme 1 Schematic illustration of the strategy for KRAS gene detection with proposed biosensor.

nanocomposite in electrochemical detection

It has been reported that anti-EGFR agents could not obtain the desired antitumor effects in chemotherapy for some part of patients suffering from non-small cell lung cancer (NSCLC). The reason is mutation of the KRAS gene, an important downstream molecule in the EGFR signal transduction pathway. Thus KRAS screening is greatly critical to determine if a patient's tumors will or not react to monoclonal antibody inhibitors of EGFR, and help the doctor to timely change treatment programs. ${ }^{36}$ Sanger sequencing, the NGS-based method, PCR and high-resolution melting analysis (HRM) have been used for KRAS gene detection, but it is limited due to the high cost and being time-consuming. ${ }^{37-42}$ Through the application of the toehold-mediated strand displacement reaction (TSDR) and isothermal DNA amplification, a fluorescent biosensor of the KRAS gene was developed, and reached a relatively low detection limit of $1.8 \mathrm{pM}$ among other fluorescent biosensors, but is not sensitive enough for gene detection or comparable to electrochemical biosensor. ${ }^{12}$ Electrochemical biosensors using enzyme capped gold nanoparticles for signal amplification were fabricated for KRAS gene detection, ${ }^{43}$ and achieved a very high sensitivity of $0.035 \mathrm{fM}$. However, the activity of the enzyme is susceptible to environmental influences, which might limit the development of field-deployed detection.

In the present work, we designed an ultrasensitive electrochemical biosensor that is based on carboxylated multiwalled carbon nanotube/molybdenum disulfide composites (MWCNTs-COOH/MoS 2 ) for detecting the KRAS gene. The procedure for target detection is presented in Scheme 1. Firstly, a MWCNTs-COOH/MoS 2 nanocomposite was prepared by the one-pot hydrothermal method. Secondly, a MWCNTs-COOH/ $\mathrm{MoS}_{2}$ nanocomposite was added on the prepared GCE electrode to immobilize the amino-modified capture probe through the amide reaction. In this step, 1-ethyl-3-(3-dimethylaminopropyl) carbodiimide (EDC) and $N$-hydroxysuccinimide (NHS) played an indispensable role, EDC formed amide bonds between carboxyl of MWCNTS-COOH and the amino groups of capture probes, while NHS was used to improve the stability of EDC. With the amide reaction, the capture probe was tightly covalent to the surface of the electrode, and then the DNA/MWCNTs$\mathrm{COOH} / \mathrm{MoS}_{2}$ decorated electrode was incubated into Tris-HCl buffer containing various concentrations of target DNA, after hybridization between the capture probe and the target probe.
Table 1 Synthetic oligonucleotide sequences used in this study

\begin{tabular}{lc}
\hline \multicolumn{1}{c}{ Nucleotide name } & Sequence $\left(5^{\prime} \rightarrow 3^{\prime}\right)$ \\
\hline Capture probe & $\mathrm{NH}_{2}-\left(\mathrm{CH}_{2}\right)_{6}$-TCAACCTCGACC- \\
& ACCGCATCCGTT \\
Target DNA & AACGGATGCGGTGGTCGAG- \\
& GTTGA \\
MT-1 (Single-base mismatch) & AACGGATGCGGTGTTCGAG- \\
& GTTGA \\
MT-3 (Three-base mismatch) & AACGGAAGCGGTGTTCGAG- \\
& CTTGA \\
NCS (Non-complementary & CCTAATCTGACTTAGCGGGT- \\
sequence) & TCCC \\
\hline
\end{tabular}

Methylene blue (MB) was used as an electrochemical detection indicator that can bind with DNA strands through the electrostatic interaction. Finally, we tested the practical ability of this biosensor in human serum, and obtained a desirable result. Altogether, the designed biosensor showed wonderful sensitivity and good selectivity, suggesting that this MWCNTs$\mathrm{COOH} / \mathrm{MoS}_{2}$ nanocomposite enhanced biosensor has a promising application in molecular detection.

\section{Experimental}

\section{Reagents and materials}

All oligonucleotide sequences were synthesized and purchased from Sangon Biotechnology Co., Ltd. (Shanghai, China); the oligonucleotide sequences are listed in Table 1. The methylene blue (MB), Tris- $\mathrm{HCl}$, and ethylene-diaminetetraacetic acid disodium salt ( $\mathrm{Na}_{2}$ EDTA), $N$-hydroxysuccinimide (NHS), 1-ethyl-3-(3-dimethylaminopropyl) carbodiimide (EDC) were purchased from Sigma-Aldrich (St. Louis, MO). Potassium ferricyanide $\left(\mathrm{K}_{3} \mathrm{Fe}(\mathrm{CN})_{6}\right)$ and potassium ferrocyanide $\left(\mathrm{K}_{4} \mathrm{Fe}(\mathrm{CN})_{6}\right)$ were provided by Sinopharm Group Chemical Reagent Co., Ltd. (Beijing, China), Normal human serum were purchased from Solarbio Tech. Co., Ltd. (Beijing, China), MWCNTs$\mathrm{COOH}$ and L-cysteine were purchased from Aladdin Chemicals Co., Ltd. (Shanghai, China), $\mathrm{Na}_{2} \mathrm{MoO}_{4} \cdot 2 \mathrm{H}_{2} \mathrm{O}$ was purchased from Shanghai Chemical Reagent Corporation (Shanghai, China). Other reagents were purchased from Chongqing Chuan- 
dong Chemical Co., Ltd. All chemicals were of analytical grade. Deionized (DI) water was produced using a Milli-Q system.

\section{Instrumentations}

All electrochemical measurements were performed on a CHI660D electrochemical workstation (Shanghai $\mathrm{CH}$ Instruments Co., China) with a regular three-electrode system composed of a platinum wire as an auxiliary electrode, a saturated calomel electrode (SCE) as a reference electrode and a 3-mm diameter GCE as a working electrode. Cyclic voltammetry (CV) measurements were used to record all electrochemical properties while constructing the biosensor. DPV measurements were used for all detections of the electrochemical performance of the target DNA, and performed between 0.1 and $-0.7 \mathrm{~V}$, along with a $0.05 \mathrm{~V}$ of pulse amplitude, $0.05 \mathrm{~s}$ of the pulse width and $0.5 \mathrm{~s}$ of pulse period. The morphologies of the nanocomposites were demonstrated on a LIBRA 200 transmission electron microscope (Zeiss, Germany) and a JSM-7500F scanning electron microscope (JEOL, USA). The Fourier-transform infrared spectrum (FT-IR) was recorded on a Nicolet6700 (Thermo Fisher Scientific, USA). The X-ray photoelectron spectrum (XPS) in this work was measured on an Escalab 250Xi (Thermo Fisher Scientific, USA). The X-ray diffraction (XRD) pattern here was obtained on a Bruker D8 (Bruker, Germany).

\section{Preparation of the MWCNTs-COOH/MoS 2 nanocomposite}

MWCNTs-COOH/MoS 2 nanocomposites were prepared by the one-step hydrothermal method, as reported before. ${ }^{44}$ In order to keep the original structure of the final nanocomposites, we used a vacuum freeze-drying method to get the final material while the reported method was dried by a vacuum at $80^{\circ} \mathrm{C}$ for $20 \mathrm{~h}$. The specific process was as follows: First, $0.017 \mathrm{~g}$ MWCNTs- $\mathrm{COOH}$ was added in $40 \mathrm{~mL}$ deionized water and well dispered by ultrasonic irradiation for $20 \mathrm{~min}$. Second, $0.3 \mathrm{~g} \mathrm{Na}_{2} \mathrm{MoO}_{4} \cdot 2 \mathrm{H}_{2} \mathrm{O}$ was added with ultrasonic irradiation for 30 min. Then $\mathrm{pH}$ value was adjusted to 6.5 , followed by the addition of $0.8 \mathrm{~g}$ L-cysteine. The mixture was hardly stirred for more than $1 \mathrm{~h}$, and $40 \mathrm{~mL}$ deionized water was added during the stirring of mixture, then transferred into a $100-\mathrm{mL}$ Teflon-lined stainless-steel autoclave and kept at $180^{\circ} \mathrm{C}$ for $48 \mathrm{~h}$. After the hydrothermal reaction, the vessel was kept at room temperature and cooled, then opened in a ventilated kitchen, the composite was firstly collected by filtration and repeated washing with water, and then collected by centrifugation and washed with both distilled water and absolute ethanol, and then dried by vacuum freeze-drying for $24 \mathrm{~h}$.

\section{Fabrication of electrochemical DNA biosensor}

The fabrication process of this biosensor is shown in Scheme 1. The GCE was polished to an eligible standard with 0.3 and $0.05 \mu \mathrm{m}$ alumina slurries. It was then washed ultrasonically with ultrapure water and absolute alcohol three times, and dried with nitrogen. The concentration of the MWCNTs-COOH/MoS $\mathrm{M}_{2}$ nanocomposite we used was $2 \mathrm{mg} / \mathrm{mL}$, and then $5 \mu \mathrm{L}$ of the MWCNTs-COOH/MoS 2 nanocomposite mixture was carefully dropped on the polished GCE, and dried at room temperature. Before immobilization of the capture probe, the MWCNTs-COOH/MoS 2 composite modified electrode was incubated into a PBS buffer $(\mathrm{pH} 7.4,0.01 \mathrm{M}$, $\mathrm{NaCl}$ ) containing $5 \mathrm{mM} \mathrm{EDC}$ and $8 \mathrm{mM} \mathrm{NHS}$ for $45 \mathrm{~min}$, and then washed with PBS buffer containing $0.1 \%$ SDS (PBS buffer I) and dried with nitrogen; $5 \mu \mathrm{L}$ of the $1 \mu \mathrm{M}$ capture probe was dropped on the electrode and kept at room temperature for $2 \mathrm{~h}$ with protection of the centrifuge tube. The purpose of this step was to make sure the amino modified capture probe could be covalently immobilized on the electrode, and then washed with PBS buffer containing $0.1 \%$ SDS. Here the electrochemical biosensor was fabricated and stored in a refrigerator at $4{ }^{\circ} \mathrm{C}$ for the following steps.

\section{Hybridization with target ssDNA and electrochemical measurements}

The DNA/MWCNTs-COOH/MoS 2 modified electrode was kept in a $20 \mathrm{mM}$ Tris- $\mathrm{HCl}$ buffer $(\mathrm{pH} 7.4,20 \mathrm{mM} \mathrm{NaCl})$ containing various concentrations of the target DNA sequences at $30^{\circ} \mathrm{C}$ for $1 \mathrm{~h}$, and then rinsed with PBS buffer I to remove any non-specifically adsorbed DNA. It was incubated in a $50 \mu \mathrm{M}$ MB solution for $15 \mathrm{~min}$ and then washed smoothly with ultrapure water. Finally, the electrochemical response was operated by DPV in $0.1 \mathrm{M}$ PBS ( $\mathrm{pH} 7.40 .01 \mathrm{M} \mathrm{NaCl}$ ) on a CHI660D electrochemical workstation.

\section{Detection in normal human serum}

To investigate the practicality of this proposed biosensor, we tested the biosensor with normal human serum. Firstly, the serum was 30 -fold diluted by Tris- $\mathrm{HCl}$ buffer; secondly, $900 \mu \mathrm{L}$ diluted serum was added to $100 \mu \mathrm{L}$ of $1.0 \times 10^{-11} \mathrm{M}$ target probe and $100 \mu \mathrm{L}$ of $1.0 \times 10^{-12} \mathrm{M}$ target probe separately, and used as a hybridization solution for serum sample detection. The other step was completely the same as 2.5 .

\section{Results and Discussion}

Characterization of the MWCNTs-COOH/MoS 2 nanocomposites Here, SEM, HRTEM, FT-IR, XPS, XRD were introduced to verify the characteristic of the nanocomposite we prepared. Figure 1A clearly shows layer-nanoflowers of the $\mathrm{MoS}_{2}$ which is the same as reported, ${ }^{44}$ revealing the flower-like morphology of $\mathrm{MoS}_{2}$. An SEM image of MWCNTs-COOH was displayed in Fig. 1B, which illustrates the nanotube of MWCNTs-COOH. The MWCNTs-COOH/MoS ${ }_{2}$ composite is exhibited in Fig. 1C, showing the combination of sheets of $\mathrm{MoS}_{2}$ and nanotube MWCNTs-COOH. Moreover, Figs. 1D - II show TEM and HRTEM images of $\mathrm{MoS}_{2}$, MWCNTs-COOH and MWCNTs$\mathrm{COOH} / \mathrm{MoS}_{2}$ composites, and further demonstrates the structure of the as-prepared materials. Figures 1D - 1E obviously show the nanosheet shape of $\mathrm{MoS}_{2}$ and the nanotube structure of MWCNTs-COOH. Figure 1F clearly shows the good admixture and insert of MWCNTs-COOH/MoS 2 composites. As shown in Figs. $1 \mathrm{G}-1 \mathrm{H}$, the lattice spacing of MWCNTs-COOH/MoS was $0.68 \mathrm{~nm}$, the lattice spacing of $\mathrm{MoS}_{2}$, and the lattice spacing of MWCNTs-COOH were $0.48 \mathrm{~nm}$. According to the increase of the lattice spacing between $\mathrm{MoS}_{2}$ spacers and the decrease of MWCNTs-COOH spacers, we could draw the conclusion that the MWCNTs-COOH was inserted and wrapped around the $\mathrm{MoS}_{2}$.

The FT-IR spectrum (Fig. 2) was obtained between 4000 and $400 \mathrm{~cm}^{-1}$. The $\mathrm{O}-\mathrm{H}$ absorption peaks appearing at 3430 and $1630 \mathrm{~cm}^{-1}$ were due to the stretching vibration and bending vibration of the adsorbed water between the molecular layers; the bands nearby $1384 \mathrm{~cm}^{-1}$ appearing in all of these three samples were attributed to stretching vibrations of the $\mathrm{C}-\mathrm{O}$ bonds. The absorption peaks appearing at $1120 \mathrm{~cm}^{-1}$ were due to the asymmetry and symmetric stretching vibration of the $\mathrm{S}=\mathrm{O}$ functional group. The peaks of MWCNTs-COOH/MoS 2 which appeared at $600 \mathrm{~cm}^{-1}$ were assigned to Mo-S vibration, and the absorption peaks, which belong to MWCNTs-COOH/MoS 2 and $\mathrm{MoS}_{2}$, appearing at nearby $956 \mathrm{~cm}^{-1}$ was derived from the stretching vibration of the Mo-O, suggesting that the 

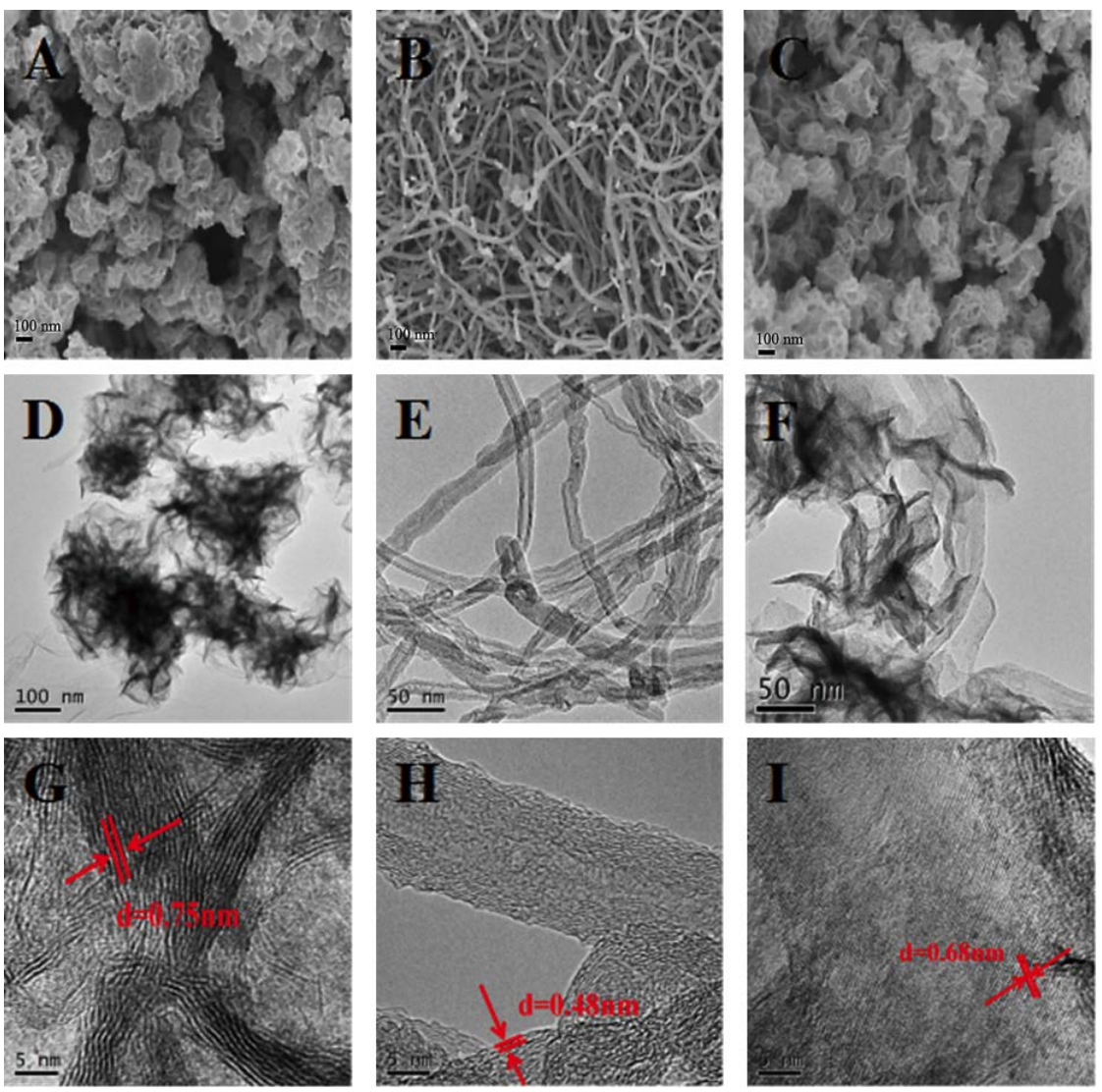

Fig. 1 SEM images of $\mathrm{MoS}_{2}$ nanosheets (A), MWCNTs-COOH (B) and MWCNTs-COOH/MoS composites (C); HRTEM images of $\mathrm{MoS}_{2}$ nanosheets (D, G), MWCNTs-COOH (E, H) and MWCNTs$\mathrm{COOH} / \mathrm{MoS}_{2}$ composites (F, I).

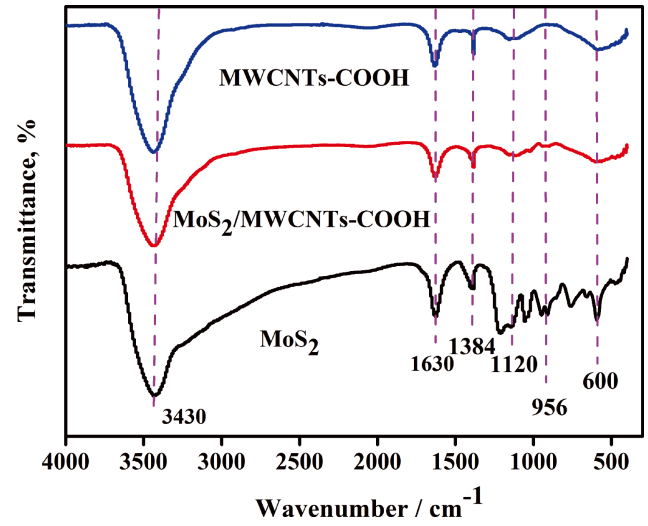

Fig. 2 IR spectra of $\mathrm{MoS}_{2}$ nanosheets, MWCNTs-COOH and MWCNTs-COOH/MoS 2 composites.

MWCNTs-COOH/MoS 2 was well prepared. ${ }^{44,45}$

All of the above results were proved to be consistent with the findings in Fig. 3, which display the XRD pattern of $\mathrm{MoS}_{2}$, MWCNTs-COOH and MWCNTs-COOH/MoS 2 composite, respectively. Since we could see in Fig. 3, the $\mathrm{MoS}_{2}$ accurately displayed the crystalline peaks at $2 \theta=13.65,33.12,42.84$ and $56.42^{\circ}$ corresponding to the (002), (100), (103), and (110) planes of $\mathrm{MoS}_{2}$ (JCPDS No. 37-1492), respectively. ${ }^{46}$ For MWCNTs-COOH, the typical diffraction peaks that appeared at $2 \theta=25.91$ and $43.82^{\circ}$ were considered to be (002) and (100) reflections of the hexagonal graphite structure, revealing the

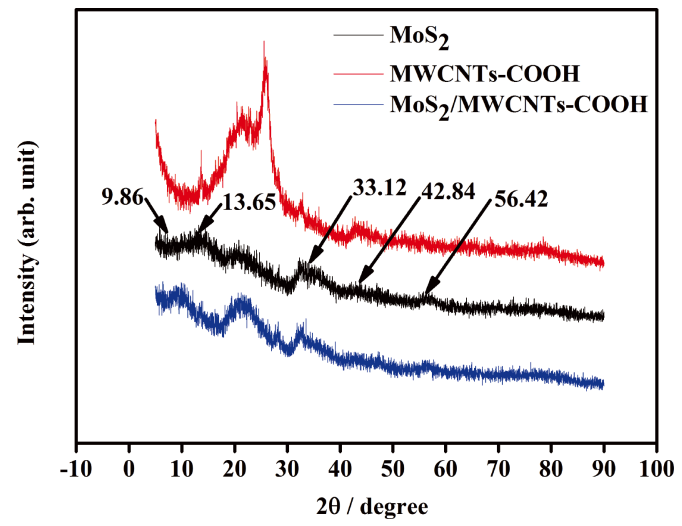

Fig. 3 XRD patterns of $\mathrm{MoS}_{2}$ nanosheets, MWCNTs-COOH and MWCNTs-COOH/MoS 2 composites.

high electrical conductivity of MWCNTs-COOH. ${ }^{47}$ For the MWCNTs-COOH/MoS 2 composites, the typical diffraction peaks assigned to the (002) plane of $\mathrm{MoS}_{2}$ were absent, showing that the $\mathrm{MoS}_{2}$ of the composites was single-layer. Other diffraction peaks of $\mathrm{MoS}_{2}$ were rather weak because the MWCNTs-COOH was inserted in the composite and the flower like $\mathrm{MoS}_{2}$ transformed into less layer structure. The major diffraction peaks of MWCNT were weaker, because $\mathrm{MoS}_{2}$ nanosheets reduced the stacking of MWCNTs- $\mathrm{COOH}$, while the insert of MWCNTs-COOH between $\mathrm{MoS}_{2}$ nanosheets induced a larger layer-space of the $\mathrm{MoS}_{2}$ nanosheets attributed to the 

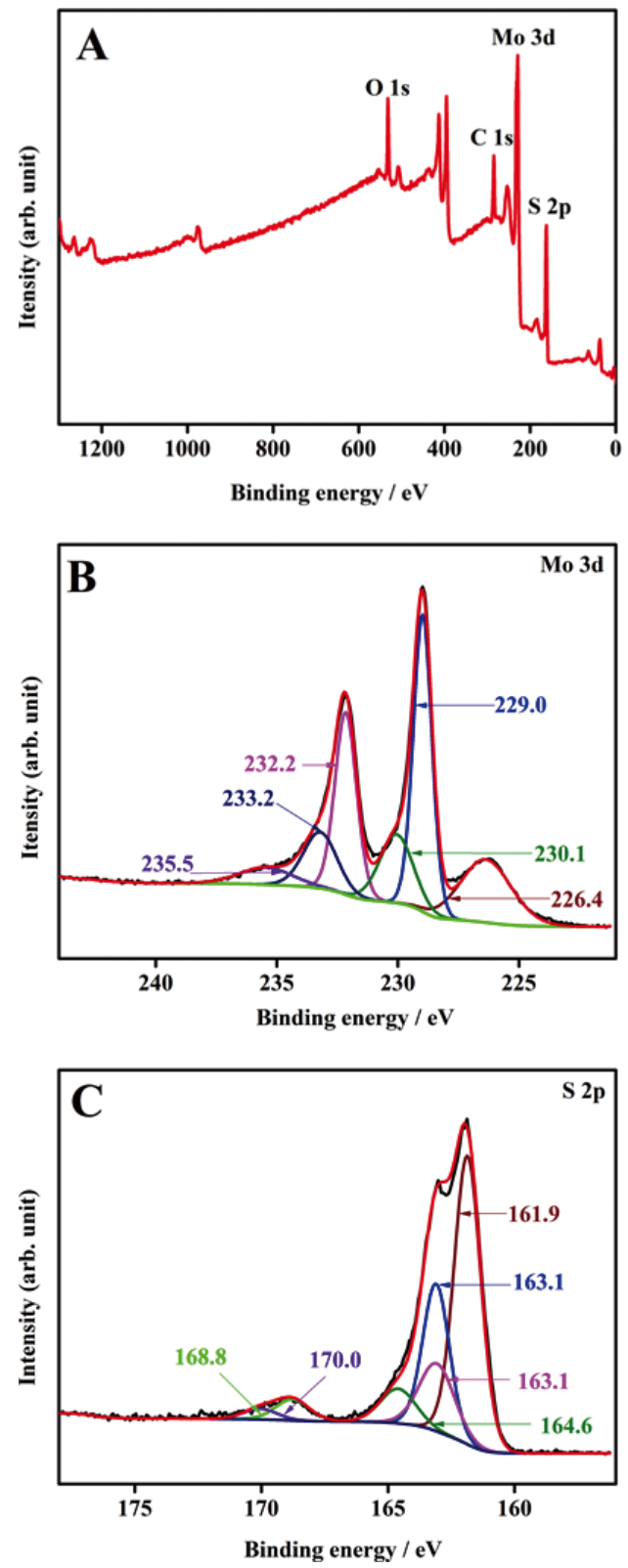

Fig. 4 XPS survey spectra of MWCNTs-COOH/MoS 2 : overall survey MWCNTs-COOH/MoS 2 (A); high-resolution Mo 3d XPS spectra of MWCNTs-COOH/MoS 2 (B); high-resolution S 2s XPS spectra of MWCNTs-COOH/MoS $2(\mathrm{C})$.

diffraction peaks appearing at $2 \theta=9.82^{\circ} .{ }^{48}$ This demonstrated the successful preparation of MWCNTs-COOH/MoS composites.

To further confirm the MWCNTs-COOH/MoS 2 , an XPS study was introduced. Figure 4A shows the overall survey MWCNTs$\mathrm{COOH} / \mathrm{MoS}_{2}$; the appearance of $\mathrm{C}$, Mo and $\mathrm{S}$ revealed a successful preparation of the materials. High-resolution Mo $3 \mathrm{~d}$ XPS spectra of MWCNTs-COOH/MoS 2 (Fig. 4B) show the three typical main peaks of Mo $3 \mathrm{~d}_{5 / 2}(229.0 \mathrm{eV})$, Mo $3 \mathrm{~d}_{3 / 2}$ $(232.2 \mathrm{eV})$ and $\mathrm{S} 2 \mathrm{~s}$ for $\mathrm{MoS}_{2}(226.4 \mathrm{eV})$. The high binding energy peak of Mo $3 \mathrm{~d}(235.5 \mathrm{eV})$ and other two high binding energy peak of Mo $3 \mathrm{~d}_{3 / 2}(233.2 \mathrm{eV})$, Mo $3 \mathrm{~d}_{5 / 2}(230.1 \mathrm{eV})$ was considered to be the peak $\mathrm{MoO}_{3}$, due to the preparation of the catalyst. $^{30,49}$ Figure $4 \mathrm{C}$ shows the S $2 p$ peak, which contains three doublets. The doublet at S $2 \mathrm{p}_{3 / 2}=161.9 \mathrm{eV}$ and S $2 \mathrm{p}_{1 / 2}=$ $163.1 \mathrm{eV}$ was assigned to the $\mathrm{S} 2 \mathrm{p}_{3 / 2}$ and $\mathrm{S} 2 \mathrm{p}_{1 / 2}(\mathrm{C}-\mathrm{S}-\mathrm{C})$ lines of

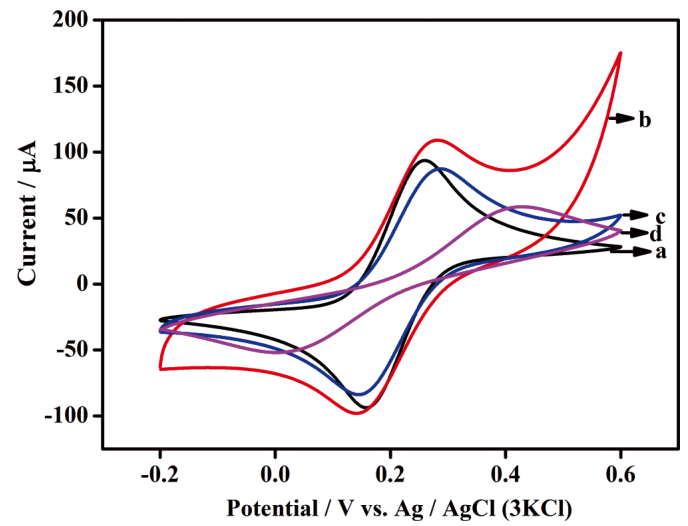

Fig. 5 Cyclic voltammograms of different modified electrodes in $1.0 \mathrm{mM} \mathrm{Fe}(\mathrm{CN}) 6^{3-14-}$ containing $0.1 \mathrm{M} \mathrm{KCl}$ solution of this biosensor. Bare GCE (a), MWCNTs-COOH/MoS $/$ GCE (b), ssDNA/ MWCNTs$\mathrm{COOH} / \mathrm{MoS}_{2} / \mathrm{GCE}$ (c), dsDNA/MWCNTs-COOH/MoS $/$ GCE (d).

$\mathrm{MoS}_{2}$, and the binding energy at S $2 \mathrm{p}_{3 / 2}=163.1 \mathrm{eV}$ and S $2 \mathrm{p}_{1 / 2}$ $=164.6 \mathrm{eV}$ were matched to bridging $\mathrm{S}_{2}{ }^{2}$ - and/or apical $\mathrm{S}^{2-}$ ligands. High-energy components appearing at 168.8 and $170.0 \mathrm{eV}$ could be explained as being high-valance $\mathrm{S}$ species $\mathrm{C}-\mathrm{SO}_{\mathrm{x}}-\mathrm{C} .{ }^{50,51}$

\section{Electrochemical behavior of modified electrodes}

$\mathrm{CV}$ measurements were used to charactering the electrochemical processes. The $\mathrm{CV}$ curves were recorded in a $1.0 \mathrm{mM}\left[\mathrm{Fe}(\mathrm{CN})_{6}\right]^{3-14}$ solution containing $0.1 \mathrm{M} \mathrm{KCl}$ at a scan rate of $50 \mathrm{mV} \mathrm{s}^{-1}$; the potential scanning range was from -0.2 to $0.6 \mathrm{~V}$. Curves from a to d (Fig. 5) represent different kinds of modified electrodes; the MWCNTs-COOH/MoS ${ }_{2}$ enhanced electrode (curve b) shows a higher redox peak current than the polished bare electrode (curve a) because of the good conductivity of the nanocomposites. After incubation of the capture DNA, the redox peak current of the ssDNA/MWCNTs$\mathrm{COOH} / \mathrm{MoS}_{2}$ modified electrode (curve c) decreased because of the negatively charged DNA. When target DNA $\left(1.0 \times 10^{-7} \mathrm{M}\right)$ was added for successful hybridization, the peak current further declined (curve d), because of blocking of the electron transfer on the surface, which was caused by the double-stranded structure of the capture-target DNA. ${ }^{52-54}$

\section{Optimization of experimental conditions}

To optimize the detection conditions of the target DNA the operational conditions were investigated, including the temperature and time of double-stranded hybridization reactions, the incubation time of $\mathrm{MB}$, and the concentration of MB used at the last step, respectively. The concentration of the target DNA we used in this part was $1.0 \times 10^{-7} \mathrm{M}$. The results could be recorded by DPV curves.

As shown in Fig. 6A, the current grew while the hybridization time was increasing from 20 to $80 \mathrm{~min}$, and reached to the maximum value after $60 \mathrm{~min}$, and then basically remained stable, indicating that hybridization of DNA has completely finished; $60 \mathrm{~min}$ is thus the optimal hybridization time. Figure 6B shows that the hybridization temperature was monitored in a range from 27 to $33^{\circ} \mathrm{C}$. It can be observed that the signal increased as the temperature increased from 27 to $30^{\circ} \mathrm{C}$, but decreased from over 30 to $33^{\circ} \mathrm{C}$, indicating that $30^{\circ} \mathrm{C}$ is the optimum temperature for DNA hybridization reactions. Moreover, the incubation time of MB was carried out from 15 to 20 min; as we can see from Fig. 6C, this did not change a lot, 

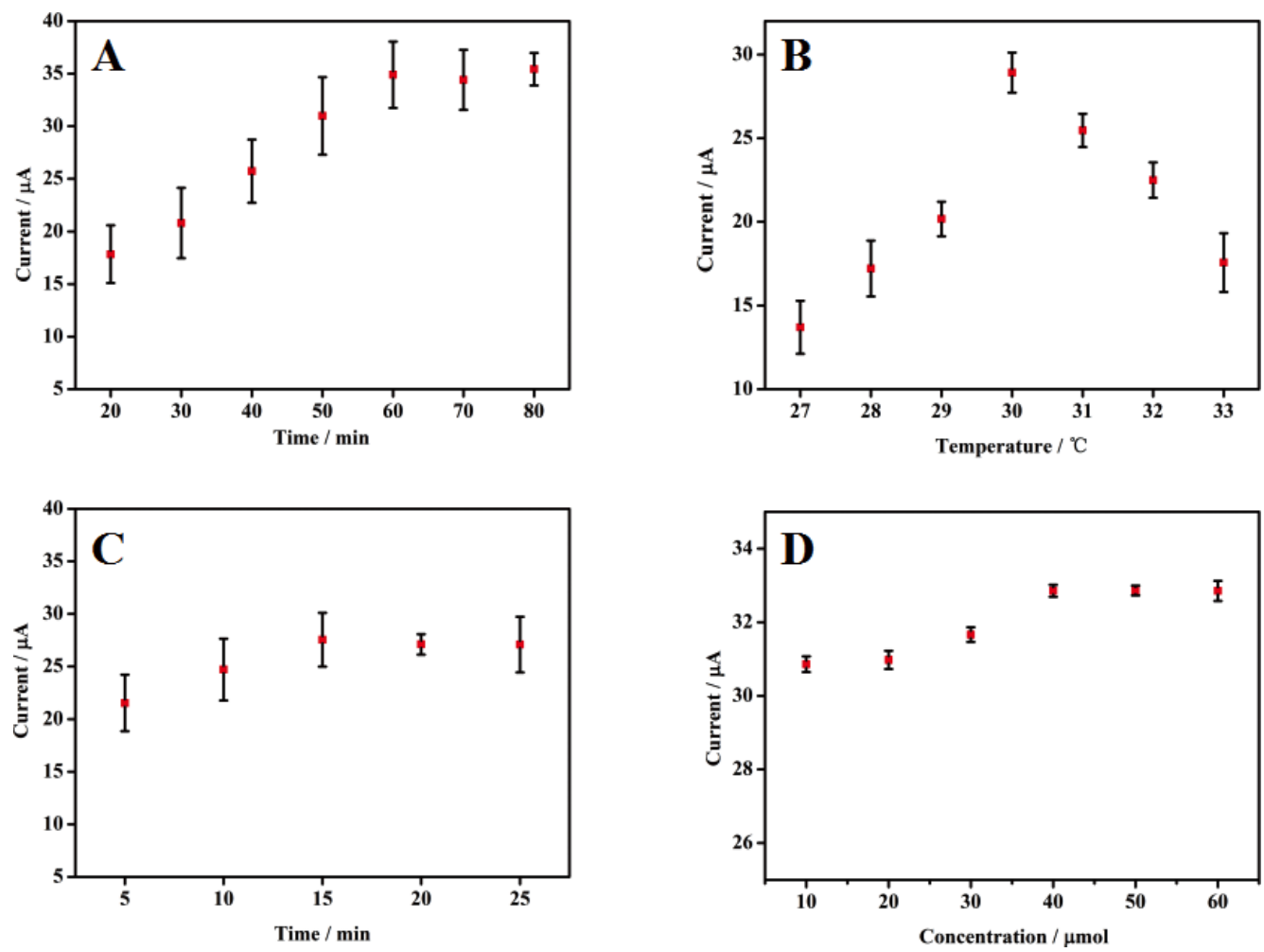

Fig. 6 Optimization of the experimental conditions: (A) effects of hybridization time, (B) effects of hybridization temperature, (C) effects of incubation time of MB, (D) effects of concentration of MB.

so we chose $15 \mathrm{~min}$ as the optimized incubation time of MB. Also, the ultimate concentration of $\mathrm{MB}$ was set as $50 \mu \mathrm{M}$ after being optimized, as shown in Fig. 6D.

\section{Analytical performance of the DNA biosensor}

To investigate the analytical performance of the MWCNTs$\mathrm{COOH} / \mathrm{MoS}_{2}$ based DNA biosensor, different concentrations of target DNA were added and incubated under the optimal conditions. The DPV measurement was the main technology used in this part to record the change in current. It can be clearly observed that the signal intensity of $\mathrm{MB}$ was growing along with the increasing concentration of target DNA (Fig. 7A). The calibration plot illustrated that this biosensor holds a nice linear relationship between the electrochemical currents and the logarithm of the concentration of target DNA from $1.0 \times 10^{-14}$ to $1.0 \times 10^{-7} \mathrm{M}$, as shown in Fig. $7 \mathrm{~B}$, with a correlation coefficient of 0.9978 . The linear-regression equation was $I(\mathrm{~A})=50.95+3.39 \log C(\mathrm{M})$, and the actual detection limit was $3 \mathrm{fM}$. Compared with other reported electrochemical biosensors for oligonucleotide sequences detection (Table 2), the biosensor of this work had reached a relatively lower detection limit or a relatively wider detection range. We found that the flower-like $\mathrm{MoS}_{2}$ exceed the reaction surface for detection, while the insert of MWCNTs-COOH increased the conductivity of the electrode. Therefore, we can conclude that this MWCNTs-COOH/MoS 2 nanocomposite that enhanced the biosensor had a good electrochemical performance of high sensitivity.

\section{Specificity, stability and reproducibility of biosensor}

The specificity of the sensor was studied by comparing three different kinds of interferences: single-base mismatch (MT-1), three-base mismatch (MT-3) and noncomplementary probe
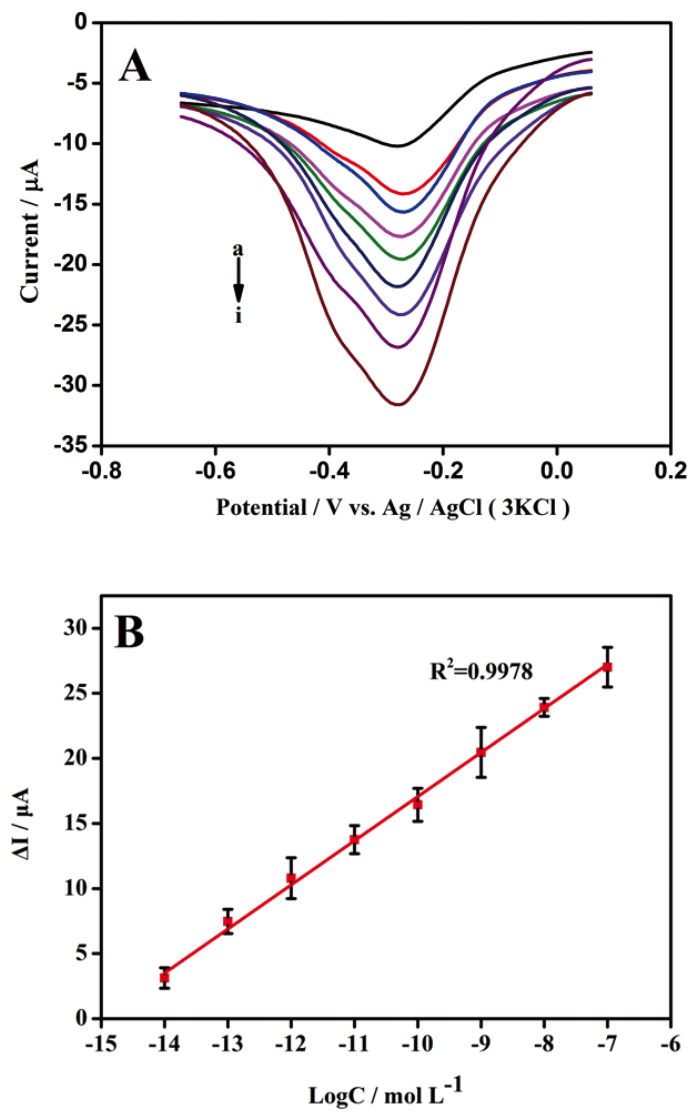

Fig. 7 (A) DPV curves after hybridization with increasing concentrations of target ssDNA (from a to i): $0,1.0 \times 10^{-14}, 1.0 \times 10^{-13}$, $1.0 \times 10^{-12}, 1.0 \times 10^{-11}, 1.0 \times 10^{-10}, 1.0 \times 10^{-9}, 1.0 \times 10^{-8}$, and $1.0 \times$ $10^{-7}$ M. (B) Logarithmic plot of peak current $v s$. the concentration of target ssDNA. 
Table 2 Comparison of linear ranges and detection limits of the different electrochemical biosensors

\begin{tabular}{llccc}
\hline \multicolumn{1}{c}{ Modified electrode } & Detection technique & Linear range/M & Detection limit/fM & Reference \\
\hline GOD/AuNPs/MoS $/ \mathrm{MWCNTs} / \mathrm{GCE}$ & CV & $1.0 \times 10^{-14}-1.0 \times 10^{-8}$ & 0.79 & 44 \\
$\mathrm{MoS}_{2} /$ carbon aerogel/GCE & DPV & $1.0 \times 10^{-12}-1.0 \times 10^{-8}$ & 300 & 46 \\
Thin-layer $\mathrm{MoS}_{2} / \mathrm{GCE}$ & DPV & $1.0 \times 10^{-16}-1.0 \times 10^{-10}$ & 0.019 & 55 \\
$\mathrm{AuNPs}_{\mathrm{MoS}} / \mathrm{GCE}$ & EIS & $1.0 \times 10^{-14}-1.0 \times 10^{-9}$ & 0.45 & 56 \\
$\mathrm{ZnO} / \mathrm{MoS}_{2}$ & DPV & $1.0 \times 10^{-15}-1.0 \times 10^{-6}$ & 0.66 & 57 \\
$\mathrm{CdS}_{\mathrm{MoS}}$ & Photocurrent response & $1.0 \times 10^{-15}-1.0 \times 10^{-10}$ & 0.39 & 58 \\
$\mathrm{MWCNTs}_{2} \mathrm{COOH} / \mathrm{MoS}_{2} / \mathrm{GCE}$ & DPV & $1.0 \times 10^{-14}-1.0 \times 10^{-7}$ & 3 & This work \\
\hline
\end{tabular}

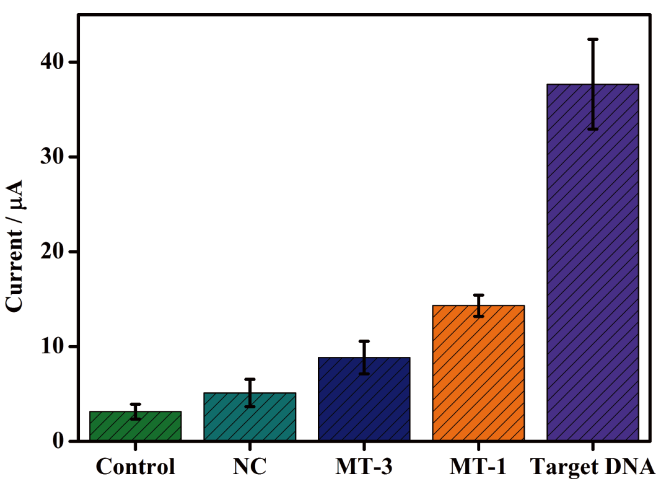

Fig. 8 Comparison of DPV responses of the blank and the four different types of DNA sequences (single-base mismatch target, MT-1; three-base mismatch target, MT-2; noncomplementary sequence, NCS). The concentration of different DNA sequences was $1.0 \times 10^{-7} \mathrm{M}$.

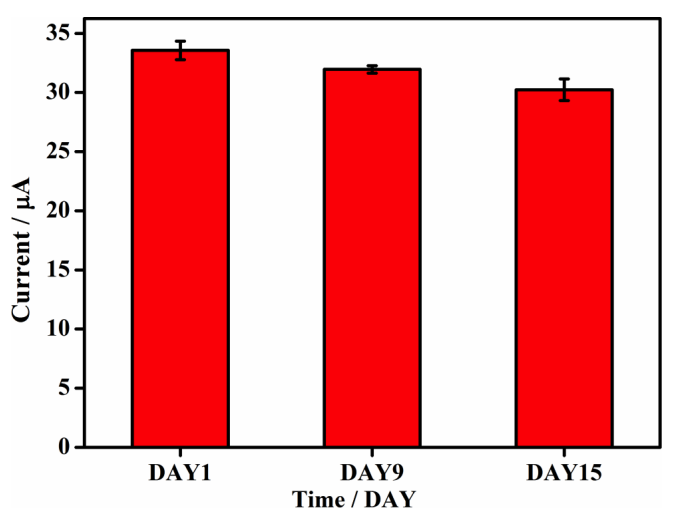

Fig. 9 Stability of this biosensor after being kept in $4^{\circ} \mathrm{C}$ refrigerator for 15 days.

(NON) with the target DNA. Figure 8 shows different current responses of each type of detector. The discrimination between the mismatch oligonucleotide and the target DNA is apparently obvious. The current of MT- 1 was $38 \%$ of the complementary target ssDNA, indicating that the base mismatch prevented completion of hybridization. The current of MT-3 was only $23 \%$ of complementary target ssDNA, and the current of NON was $13 \%$. The results indicated that this DNA biosensor holds a good selectivity and DNA mismatch recognition ability.

The reproducibility of the DNA biosensor was also analyzed by using five sensors for repeated tests with $1.0 \times 10^{-7} \mathrm{M}$ target sequences within 1 day. The relative standard deviation was $4.4 \%(n=5)$, showing acceptable reproducibility for target DNA detection. The stability of this biosensor was also studied. As shown in Fig. 9, after storage in a refrigerator at $4{ }^{\circ} \mathrm{C}$ for 15 days, the sensor still preserved about $95.2 \%$ of peak current
Table 3 Determination result of the KRAS gene in serum samples with the biosensor (each result was the average of three determinations)

\begin{tabular}{cccc}
\hline $\begin{array}{c}\text { Sample } \\
\text { No. }\end{array}$ & $\begin{array}{c}\text { DNA } \\
\text { added/M }\end{array}$ & $\begin{array}{c}\text { Average value of } \\
\text { DNA/M }\end{array}$ & $\begin{array}{c}\text { Recovery, } \\
\%\end{array}$ \\
\hline 1 & $1.0 \times 10^{-11}$ & $9.56449 \times 10^{-12}$ & 95.64 \\
2 & $1.0 \times 10^{-12}$ & $9.84226 \times 10^{-13}$ & 98.42 \\
\hline
\end{tabular}

compared with the initial response current value, which showed that the DNA sensor had good stability and could be considered to have a good ability for application studies.

\section{KRAS gene detection in normal human serum}

To improve the practicality of the DNA sensor, we investigated recovery experiments by detecting different amounts of target DNA in serum samples from normal people. The interference effect of the complicated biological fluids was measured by DPV. As shown in Table 3, the recoveries obtained were 95.64 and $98.42 \%$ with RSD of 2.0 and $2.4 \%$, (which added 10 and $1 \mathrm{pM}$, to diluted serum respectively), revealing that the fabricated biosensor is reliable for the detection and diagnosis of the KRAS gene in serum samples.

\section{Conclusion}

Hence, we have fabricated an ultrasensitive electrochemical biosensor based on MWCNTs-COOH/ $\mathrm{MoS}_{2}$ nanocomposites for detecting the KRAS gene. Introducing the MWCNTs$\mathrm{COOH} / \mathrm{MoS}_{2}$ nanocomposite can excellently improve the detection capacity. The nanocomposite can exceed the immobilization area for the capture, while MWCNTs-COOH elevates the conductivity of the electrode. The biosensor exhibited a low detection limit of $3 \mathrm{fM}$, a wide linear range with $1.0 \times 10^{-14}$ to $1.0 \times 10^{-7} \mathrm{M}$, and presented outstanding sensitivity. Therefore, we believe that this displayed biosensor can play a critical role in the on-time screening of DNA in molecular diagnosis.

\section{Acknowledgements}

This work was supported by the National Natural Science Foundation of China (81772290 and 31000425), the Fundamental Research Funds for the Central Universities (No. 2018CDXYSW0023) and the Research Project of Chongqing Science and Technology Commission of China (CSTC, 2010BB5226). 


\section{References}

1. A. Pennycuick, T. Simpson, D. Crawley, R. Lal, G. Santis, P. Cane, K. Tobal, and J. Spicer, Int. J. Clin. Pract., 2012, 66, 748.

2. K. L. Spindler, N. Pallisgaard, R. F. Andersen, I. Brandslund, and A. Jakobsen, PLoS One, 2015, 10, e0108247.

3. N. Y. Cho, M. Choi, B. H. Kim, Y. M. Cho, K. C. Moon, and G. H. Kang, Int. J. Cancer, 2006, 119, 1858.

4. W. Ma, S. Brodie, S. Agersborg, V. A. Funari, and M. Albitar, Mol. Diagn. Ther, 2017, 21, 571.

5. C. S. Pareek, R. Smoczynski, and A. Tretyn, J. Appl. Genet., 2011, 52, 413 .

6. C. Jing, X. Mao, Z. Wang, K. Sun, R. Ma, J. Wu, and H. Cao, Mol. Med. Rep., 2018, 18, 2191.

7. S. Tierling, C. Sers, A. Lehmann, and J. Walter, Int. J. Cancer, 2012, 130, 567.

8. Y. Zhang, L. Wang, F. Luo, B. Qiu, L. Guo, Z. Weng, Z. Lin, and G. Chen, Chem. Commun., 2017, 53, 2910.

9. A.-M. Chiorcea-Paquim, S. C. B. Oliveira, V. C. Diculescu, and A. M. O. Brett, in "Comprehensive Analytical Chemistry (CAC) Series", ed. D. Barcelo, P.-D. Hansen, and I. Palchetti, 2017, Elsevier, 287.

10. S. Kurbanoglu, B. Dogan-Topal, E. P. Rodriguez, B. BozalPalabiyik, S. A. Ozkan, and B. Uslu, J. Electroanal. Chem., 2016, 775,8 .

11. L. Wu, J. Deng, X. Tan, W. Yin, F. Ding, and H. Han, Sens. Actuators, B, 2018, 254, 206.

12. J. Zhu, Y. Ding, X. Liu, L. Wang, and W. Jiang, Biosens. Bioelectron., 2014, 59, 276.

13. X. Zhang, H. Xu, L. Han, N. Li, and H. Luo, Anal. Sci., 2018, 34, 149

14. N. Soh, Anal. Sci., 2018, 34, 515.

15. K. Sawamura and M. Hashimoto, Anal. Sci., 2017, 33, 1457.

16. V. Jayanthi, A. B. Das, and U. Saxena, Biosens. Bioelectron., 2017, 91, 15.

17. S. Kumar, W. Ahlawat, R. Kumar, and N. Dilbaghi, Biosens. Bioelectron., 2015, 70, 498.

18. X. Zhu, M. Huang, J. Li, H. He, X. Zhang, and S. Wang, Anal. Sci., 2017, 33, 585.

19. C. He, Y. Tang, S. Wang, J. Liu, Y. Chen, Y. Dong, H. Su, and T. Tan, Anal. Sci., 2017, 3, 1155.

20. S. Takalkar, H. Xu, J. Chen, K. Baryeh, W. Qiu, J. Zhao, and G. Liu, Anal. Sci., 2016, 32, 617.

21. C. Zhu, D. Du, and Y. Lin, Biosens. Bioelectron., 2017, 89, 43.

22. X. Li, J. Li, X. Wang, J. Hu, X. Fang, X. Chu, Z. Wei, J. Shan, and X. Ding, Integr. Ferroelectr., 2015, 158, 26.

23. S. Barua, H. S. Dutta, S. Gogoi, R. Devi, and R. Khan, ACS Appl. Nano Mater., 2018, $1,2$.

24. F. P. Novais Antunes, V. S. Vaiss, S. R. Tavares, R. B. Capaz, and A. A. Leitão, Comput Mater. Sci., 2018, 152, 146.

25. J. Sun, X. Li, W. Guo, M. Zhao, X. Fan, Y. Dong, C. Xu, J. Deng, and Y. Fu, Crystals, 2017, 7, 198.

26. Q. H. Wang, K. Kalantar-Zadeh, A. Kis, J. N. Coleman, and M. S. Strano, Nat. Nanotechnol., 2012, 7, 699.

27. Z. Gao, Y. Li, X. Zhang, J. Feng, L. Kong, P. Wang, Z. Chen, Y. Dong, and Q. Wei, Biosens. Bioelectron., 2018, 102, 189

28. H.-Y. Chen, J. Wang, L. Meng, T. Yang, and K. Jiao, Chin. Chem. Lett., 2016, 27, 231.

29. K. J. Huang, Y. J. Liu, Y. M. Liu, and L. L. Wang, J. Hazard. Mater., 2014, 276, 207.

30. T.-W. Lin, C.-J. Liu, and J.-Y. Lin, Appl. Catal., B, 2013,
$134-135,75$

31. W.-K. Jo and N. C. Sagaya Selvam, Appl. Catal., A, 2016 , $525,9$.

32. P. Chen, X. Liang, Y. Xu, Y. Zhou, and W. Nie, Appl. Surf. Sci., 2018, 440, 1143.

33. X. Lin, Y. Ni, and S. Kokot, Biosens. Bioelectron., 2016 79,685 .

34. H. L. Shuai, K. J. Huang, Y. X. Chen, L. X. Fang, and M. P. Jia, Biosens. Bioelectron., 2017, 89, 989.

35. M. S. Rahman, M. S. Anower, M. K. Rahman, M. R. Hasan, M. B. Hossain, and M. I. Haque, Optik, 2017, 140, 989.

36. S. Wang, T. An, J. Wang, J. Zhao, Z. Wang, M. Zhuo, H. Bai, L. Yang, Y. Zhang, X. Wang, J. Duan, Y. Wang, Q. Guo, and M. Wu, Clin. Cancer Res., 2010, 16, 1324.

37. E. Mack, K. Stabla, J. Riera-Knorrenschild, R. Moll, A Neubauer, and C. Brendel, BMC Cancer, 2016, 16, 585.

38. D. Le Corre, A. Luscan, A. Cazes, K. Pallier, J. F. Emile, P. Laurent-Puig, and H. Blons, Exp. Mol. Pathol., 2012, 92, 275.

39. D. Sefrioui, F. Mauger, L. Leclere, L. Beaussire, F. Di Fiore, J. F. Deleuze, N. Sarafan-Vasseur, and J. Tost, Clin. Chim. Acta, 2017, 465, 1.

40. K. Tuononen, S. Maki-Nevala, V. K. Sarhadi, A. Wirtanen, M. Ronty, K. Salmenkivi, J. M. Andrews, A. I. TelarantaKeerie, S. Hannula, S. Lagstrom, P. Ellonen, A. Knuuttila, and S. Knuutila, Genes, Chromosomes Cancer, 2013, 52, 503.

41. N. Kothari, M. J. Schell, J. K. Teer, T. Yeatman, D. Shibata, and R. Kim, J. Clin. Pathol., 2014, 67, 764.

42. M. Matsunaga, T. Kaneta, K. Miwa, W. Ichikawa, K. I. Fujita, F. Nagashima, J. Furuse, M. Kage, Y. Akagi, and Y. Sasaki, Oncol. Lett., 2016, 12, 150.

43. X. Fang, L. Bai, X. Han, J. Wang, A. Shi, and Y. Zhang, Anal. Biochem., 2014, 460, 47.

44. K. J. Huang, Y. J. Liu, H. B. Wang, Y. Y. Wang, and Y. M. Liu, Biosens. Bioelectron., 2014, 55, 195.

45. H. Cai, X. Cao, Y. Jiang, P. He, and Y. Fang, Anal. Bioanal. Chem., 2003, 375, 287.

46. L. X. Fang, K. J. Huang, and Y. Liu, Biosens. Bioelectron., 2015, 71, 171.

47. Z. Shi, W. Kang, J. Xu, Y. Sun, M. Jiang, T. Ng, H. Xue, D. Y. W. Yu, W. Zhang, and C. Lee, Nano Energy, 2016, 22, 27.

48. Z. Wang, S. Dong, M. Gui, M. Asif, W. Wang, F. Wang, and H. Liu, Anal. Biochem., 2018, 543, 82.

49. S. Hua, D. Qu, L. An, G. Xi, G. Chen, F. Li, Z. Zhou, and Z. Sun, Chin. J. Catal., 2017, 38, 1028.

50. H. Wang, P. Skeldon, and G. Thompson, Surf. Coat Technol., 1997, 91, 200.

51. E. Heydari-Bafrooei and S. Askari, Int. J. Hydrogen Energy, 2017, 42, 2961.

52. J. Chen, C. Yu, Y. Zhao, Y. Niu, L. Zhang, Y. Yu, J. Wu, and J. He, Biosens. Bioelectron., 2017, 91, 892.

53. L. Zuo, Q. Qu, L. Li, X. Ran, J. Gui, Q. Wang, X. Cui, and C. Jiang, Electroanalysis, 2018, 30, 910.

54. A. Benvidi, A. Dehghani Firouzabadi, M. Dehghan Tezerjani, S. M. Moshtaghiun, M. Mazloum-Ardakani, and A. Ansarin, J. Electroanal. Chem., 2015, 750, 57.

55. X. Wang, F. Nan, J. Zhao, T. Yang, T. Ge, and K. Jiao, Biosens. Bioelectron., 2015, 64, 386.

56. S. Su, W. Cao, W. Liu, Z. Lu, D. Zhu, J. Chao, L. Weng, L. Wang, C. Fan, and L. Wang, Biosens. Bioelectron., 2017, 94, 552

57. T. Yang, M. Chen, Q. Kong, X. Luo, and K. Jiao, Biosens. Bioelectron., 2017, 89, 538.

58. Y. Zang, J. Lei, Q. Hao, and H. Ju, Biosens. Bioelectron., 2016, 77, 557. 